\title{
Modelo de monitoramento ambiental sistemático para decisão em Políticas Públicas
}

\author{
Jair Cunha Cardoso Filho \\ Rogério Henrique de Araújo Júnior \\ Universidade de Brasília - UnB, Brasil
}

REVIEW

\begin{abstract}
Resumo
Aborda a interdisciplinaridade existente entre a Ciência da Informação e as políticas públicas, e propõe a ferramenta do monitoramento ambiental como instrumento relevante para o aprimoramento do processo de avaliação da efetividade social de políticas e de programas sociais, aí incluído o Poder Legislativo, por meio da coleta, tratamento e disponibilização de informações que possibilitem identificar as mudanças ambientais e propor, de forma consistente, o aperfeiçoamento de políticas públicas que atendam às demandas dos cidadãos.
\end{abstract}

Palavras-chave

Avaliação de políticas públicas; Monitoramento ambiental; Poder Legislativo

\section{Systematic environmental monitoring model for decision in Public Policy}

\begin{abstract}
Addresses the existing interdisciplinary between Information Science and public policies, and proposes to environmental monitoring tool as a relevant tool for improving the process of evaluating the effectiveness of these social policies and social programs, there included the legislative branch, through the collection, processing and provision of information allowing to identify the environmental changes and propose, consistently, the improvement of public policies that meet the demands of citizens.
\end{abstract}

Keywords

Evaluation of public policies; Environmental monitoring; Legislative branch

\section{Introdução}

Um aspecto a ser considerado no âmbito da construção de um modelo de monitoramento ambiental sistemático para decisão em políticas públicas é a interdisciplinaridade, que também permeia a ciência da informação. Esta constatação serve de argumento para a formulação do objetivo do presente trabalho, que é o de propor subsídios para uma interlocução entre a formulação de políticas públicas e o campo da ciência da informação.

Partindo do campo da Ciência da Informação $(\mathrm{Cl})$, este trabalho propõe a utilização do monitoramento ambiental como instrumento relevante para o processo de avaliação da efetividade social das políticas públicas e programas sociais de governo. Efetividade social, de acordo com Belloni, Magalhães e Sousa (2007), é um critério de avaliação que tem por foco os resultados objetivos e práticos, tanto econômicos quanto sociais, da aplicação das políticas públicas ou dos programas sociais de governo. Sano e Montenegro Filho (2013) complementam o conceito ao afirmarem que efetividade está relacionada ao impacto social que procura identificar os efeitos produzidos sobre uma população-alvo de um dado programa social.

Segundo Moresi (2001):

Sob a perspectiva da informação, qualquer mudança ou desenvolvimento no ambiente externo cria sinais e mensagens para os quais uma organização deve estar atenta. Alguns desses sinais são fracos (difíceis de serem detectados), alguns são confusos (difíceis de serem analisados) e outros são 
espúrios (não indicam mudanças verdadeiras). Na busca de informações, a organização tem que observar seletivamente a grande quantidade de sinais criados em um ambiente dinâmico, interpretar as mensagens confusas e perceber os indícios relativos à suas atividades e objetivos. (MORESI, 2001, p.25)

Nessa direção o artigo sugere, também, o monitoramento ambiental como a ferramenta mais expressiva para coleta e mapeamento de sinais e informações no ambiente externo, além de constituir-se como suporte à aprendizagem organizacional das organizações no tema das políticas públicas.

A premissa é que o monitoramento ambiental, ao permitir o acompanhamento e a análise de informações do ambiente externo, tais como mudanças econômicas, sociais, culturais, tecnológicas em evidência ou tendentes a acontecer, oferece a possibilidade de antecipação de solução de problemas e tomada de decisão estratégica em relação a ações de avaliação, acompanhamento e controle. Possibilita, portanto, atuação proativa e aprendizado sobre a ambiência considerada.

Parte-se do pressuposto de que as organizações, ao adotarem essa ferramenta, estarão aptas a monitorar informações estratégicas sobre o ambiente econômico e social, identificar as mudanças ambientais e propor, de forma consistente, o aperfeiçoamento de políticas públicas que atendam às demandas dos cidadãos.

Para tanto, são abordadas questões referentes à $\mathrm{Cl}$, à avaliação de políticas públicas, à inteligência competitiva e ao monitoramento ambiental apresentando, em seguida, a relação entre o monitoramento e a aprendizagem organizacional. Apresenta e descreve, ainda, algumas ferramentas de monitoramento, sugerindo formas de utilização e, finalmente, propõe considerações sobre o uso da IC no contexto do Poder Legislativo.

\section{Ciência da Informação}

Interdisciplinar e com forte dimensão social e humana, conforme enfatiza Saracevic (1995), a Ciência da Informação é definida por Borko (1968) como:

[...] uma ciência interdisciplinar que estuda as propriedades e o comportamento da informação, as forças que dirigem o fluxo e o uso da informação e as técnicas, tanto manuais como mecânicas, de processar a informação visando sua armazenagem, recuperação e disseminação (BORKO, 1968, p. 3).

No trabalho clássico de Wersig e Neveling (1975), a Ciência da Informação tem como objeto de estudo a informação em uma determinada área ou sob determinada abordagem, e:

[...] está relacionada com a organização dos processos de comunicação destinados à informação para uma clientela específica e está baseada numa necessidade social específica e o seu objeto independentemente de sua definição - tem que englobar estes processos sociais (WERSIG e NEVELING,1975, p.138).

Esses autores classificam a $\mathrm{Cl}$ em quatro categorias, considerando a orientação e o ponto de vista dado à aplicação da disciplina: a visão orientada para o fenômeno, a visão orientada para os meios, a visão orientada para a tecnologia e a visão orientada para os fins.

Assim, na perspectiva de Wersig e Neveling (1975), na visão orientada para o fenômeno considera-se a existência de um fenômeno chamado informação e que a Ciência da Informação é a ciência responsável por este fenômeno. Na visão orientada para os meios, a $\mathrm{Cl}$ concentra-se nos meios que devem ser usados na atividade prática da informação como, por exemplo, a classificação, na arquivologia e na biblioteconomia. Na visão orientada para a tecnologia, a Ciência da Informação é vista como um subsistema da Ciência da Computação interessado na armazenagem e recuperação de dados. E, na visão orientada para os fins, a Ciência da Informação é definida a partir do ponto de vista de que existem determinadas necessidades sociais a serem preenchidas, e que a $\mathrm{Cl}$ deve servir a essas necessidades e desenvolver o trabalho prático com elas relacionado.

No contexto deste artigo, será considerada a visão da $\mathrm{Cl}$ orientada para os fins, tendo em vista a proposta de instrumentalização, a partir da ambiência informacional, para ações de avaliação de políticas públicas.

Brookes (1980), coloca o homem como o centro e o objeto da Ciência da Informação, na medida em que relaciona a informação, como fonte do conhecimento, ao cerne do desenvolvimento humano. Esse modo de perceber a informação e o conhecimento pode ser encontrado na chamada equação fundamental de Brookes 
(1980), para quem conhecimento é uma estrutura de conceitos ligados por suas relações, e informação é como uma pequena parte dessa estrutura. A estrutura de conhecimento, que pode ser subjetiva ou objetiva é transformada, pela informação, em nova estrutura de conhecimento, como a seguir representada:

$$
\mathrm{K}[\mathrm{S}]+\Delta \mathrm{K}=\underset{\Delta \mathrm{l}}{\mathrm{K}}[\mathrm{S}+\Delta \mathrm{S}]
$$

A equação demonstra que um conhecimento deficiente anterior $\mathrm{K}[\mathrm{S}]$, somado a um novo conhecimento $\Delta \mathrm{K}$ adquirido por meio de uma informação $\Delta \mathrm{I}$, resulta em um novo estado de conhecimento $\mathrm{K}[\mathrm{S}+\Delta \mathrm{S}]$.

Assim, em uma perspectiva cognitiva, a Cl coloca o indivíduo como agente ativo na construção do significado das situações com as quais se depara. O indivíduo deixa de ser considerado como receptor passivo de informação, passando a ativo na interação entre a estrutura de informação e a sua estrutura conceitual própria. Os focos deixam de ser os sistemas e a tecnologia da informação, passando aos usuários como indivíduos em contínua interação com o meio e com outros indivíduos. Desse modo, a Ciência da Informação não perde de vista a dimensão social, mas ao assumir a dimensão cognitiva contemporânea, admite que somos indivíduos com formação coletiva e de sentido social, apesar de vivermos situações próprias, uma vez que os conceitos e os sentidos que usamos não são exclusivamente nossos, mas construções sociais. A ideia básica, subjacente aos estudos da Ciência da Informação, é a de que o conhecimento se dá quando a informação é percebida e aceita, de modo que toda alteração provocada no estoque mental do saber do indivíduo é oriunda da interação com estruturas de informação.

Segundo Barreto (1997), a partir dos anos 80 a informação passa a ser vista como um fator que se relaciona com o conhecimento e com o desenvolvimento humano, e considerada como agente modificador da consciência humana e do grupo social. Com isso, o objetivo da informação e de suas unidades gestoras é promover o desenvolvimento do indivíduo, de seu grupo e da sociedade, desenvolvimento entendido como acréscimo de bem estar, estágio avançado de convivência, alcançado por meio dela.

Considerando que a informação é o elemento gerador do conhecimento e este leva ao desenvolvimento e à materialidade das ideias, e que a compreensão da informação e o novo conhecimento produzido levam à construção de uma nova realidade pelo indivíduo além de modificar seu contexto social, pode-se inferir que a Ciência da Informação contém um forte conteúdo de responsabilidade social no sentido de contribuir, de modo interdisciplinar, com a tomada de decisão no processo de avaliação da efetividade social de políticas públicas implementadas e na produção de conhecimento a respeito da ambiência na qual tais políticas se desenvolvem.

\section{Avaliação de Políticas Públicas e Ciência da Informação}

A política pública, para Souza (2006), é o campo do conhecimento que busca, ao mesmo tempo, movimentar as ações governamentais e analisar essas ações e, quando necessário, propor ajustes e mudanças nos seus rumos. Quando postas em prática, as políticas públicas são implementadas e, por conseguinte, submetidas aos sistemas de acompanhamento e avaliação.

Belloni, Magalhães e Sousa (2007) definem avaliação de políticas públicas como um processo sistemático de análise de uma atividade, fatos ou coisas e de seus respectivos produtos ou resultados, que permite compreender, histórica e socialmente, todas as suas dimensões e implicações, visando estimular seu aperfeiçoamento. Com efeito, denominam de avaliação institucional aquela que se destina à avaliação de políticas, planos, projetos ou instituições. Segundo esses autores, a avaliação institucional tem como objeto instituições ou políticas públicas, em especial as políticas setoriais, tais como saúde, educação, segurança e transportes.

A proposição de uma ampla definição de avaliação feita por Aguilar e Ander-Egg (1994), a partir de definições elaboradas por outros especialistas, confirma a interdisciplinaridade existente entre o campo das políticas públicas e o da Ciência da Informação.

Para os autores, a avaliação pode ser considerada como:

Uma forma de pesquisa social aplicada, sistemática, planejada e dirigida; destinada a identificar, obter e proporcionar de maneira válida e confiável dados e informação suficiente e relevante para apoiar um juízo sobre o mérito e o valor dos diferentes componentes de um programa (tanto na fase de diagnóstico, programação ou execução), ou de um conjunto de atividades específicas que se realizam, foram realizadas ou se realizarão, com o propósito de produzir efeitos e resultados concretos; comprovando a extensão e o grau em que se deram essas conquistas, de forma tal que sirva de base ou guia para uma tomada de decisões racional e inteligente entre cursos de ação, ou para solucionar 
problemas e promover o conhecimento e a compreensão dos fatores associados ao êxito ou ao fracasso de seus resultados. (AGUILAR e ANDER-EGG, 1994, p. 31-32)

A definição de Aguilar e Ander-Egg (1994) corrobora a interdisciplinaridade existente entre o campo da avaliação de políticas públicas e o campo da Cl, coadunando-se com a proposição de Borko (1968) para a Ciência da Informação no que diz respeito ao estudo das propriedades e do comportamento da informação, das forças que dirigem o fluxo e o uso da informação e das técnicas de processamento da informação com vistas ao seu armazenamento, recuperação e disseminação. É também correlata à abordagem de Wersig e Neveling (1975), na qual a Ciência da Informação tem como objeto de estudo a informação em uma determinada área ou sob determinada abordagem, está relacionada com a organização dos processos de comunicação destinados à disponibilização da informação para uma clientela específica, regida por uma necessidade social específica e o seu objeto - independentemente de sua definição - tem que considerar estes processos sociais.

Nessa direção, e utilizando a classificação proposta por Wersig e Neveling (1975), conforme visto anteriormente, de que a Ciência da Informação, em abordagem orientada para os fins deve servir para o preenchimento de determinadas necessidades sociais, como solução estrita deve compreender a área em que a informação é considerada e, baseada em problemas práticos que devem ser resolvidos, permitir uma solução ao problema concreto que deve ser enfrentado, Santos e Cardoso Filho (2011) afirmam que, na fase de avaliação de políticas públicas,

[...] são necessários o monitoramento informacional da ambiência e seu processamento na forma de experiências e práticas documentadas e explicitadas, tanto nos aspectos tecnológico, ambiental, social, econômico e emancipatório, quanto no de resultados concretos alcançados (SANTOS e CARDOSO FILHO (2011, p. 36).

Para atender a essa finalidade, e como solução estrita, a Ciência da Informação conta com a Inteligência Competitiva (IC) que, conforme Araújo Júnior, Lopes e Perucchi (2013), é conjunto de ações sistemáticas e integradas de busca, processamento, análise e disseminação de informação que visam subsidiar os tomadores de decisão no ambiente corporativo.

Similarmente à Inteligência Competitiva, a Inteligência Estratégica Antecipativa - IEA aparece como uma concepção voltada para a busca, processamento, análise e disseminação de informação e é definida como:

o processo informacional coletivo e contínuo pelo qual um grupo de indivíduos busca (de forma voluntária) e utiliza informações antecipativas relacionadas às mudanças susceptíveis de se produzirem no ambiente exterior da empresa, com o objetivo de criar oportunidades de negócios e de reduzir riscos e incertezas em geral (LESCA, FREITAS e MUNIZ, 2006).

Para Lesca, Freitas e Muniz (2006), dentre as informações antecipativas estão os sinais fracos, possíveis de serem captados em elementos de informação dispersos e de ocorrência variada, aos quais normalmente não se presta a devida atenção, mas que, combinados com outros sinais de mesma frequência, podem induzir percepções e ações a realizar, fornecendo uma representação do ambiente presente e elementos que permitam antecipar mudanças nesse ambiente. Além disso, os sinais fracos podem apoiar o processo decisório e a ação organizacional efetiva.

Aplicando-se a Inteligência Competitiva ao contexto de avaliação de políticas públicas, infere-se que a prospecção e a tradução de sinais fracos, bem como a contextualização e a criação de sentido a respeito de fatos e evidências relacionados a dada política ou programa social, podem apontar para a necessidade de revisão ou aperfeiçoamento da ação governamental, possibilitando a tomada de decisão proativa, no que tange a ações de melhoria contínua da realidade social vigente.

Como metodologia para a operacionalização da tomada de decisão proativa, Albuquerque e Araújo Júnior (2015), propõem o levantamento de necessidades informacionais dos decisores na organização, para a montagem de um modelo de atendimento assertivo e proativo. Para tanto, sugerem as seguintes providências metodológicas:

Levantamento do perfil de consumo da informação dos usuários; identificação das fontes da informação e as negociações necessárias para acessá-las; construção dos meios de se buscar as informações a partir das fontes; tratamento das restrições de acesso existentes; definição da periodicidade de busca e entrega da informação ao demandante; elaboração das estruturas de dados para armazenar o histórico dos resultados das buscas; definição das fórmulas de cálculo de indicadores de desempenho; definição dos métodos de análise que serão utilizados; desenho dos formatos de entrega dos resultados; definição da linguagem a ser adotada na comunicação; e forma de representação e organização da informação. (ALBUQUERQUE e ARAÚJO JÚNIOR, 2015, p. 189). 
Os autores afirmam que a viabilização do processo de inteligência competitiva depende do reconhecimento nos demandantes que, invariavelmente, apresentam as mesmas necessidades informacionais sobre determinados eventos da concorrência, de todo o conhecimento obtido durante e após o processo de atendimento da demanda original, a fim de aperfeiçoar o atendimento das necessidades informacionais futuras.

\section{Monitoramento Ambiental e avaliação de Políticas Públicas}

Para a prospecção de sinais, a Inteligência Competitiva conta com a ferramenta denominada monitoramento ambiental, entendido usualmente como a aquisição e o uso da informação sobre fatos, eventos, tendências e relações entre variáveis de um ambiente externo que afetam uma organização e seu desempenho ao longo do tempo.

No contexto das políticas públicas, Garcia (2001) afirma que um dos requisitos fundamentais para a gestão de um programa:

é estar permanentemente informado sobre aspectos cruciais de sua implementação, o que demanda a organização de um sistema de monitoramento de tudo o que for técnica e politicamente relevante em um programa e das ações pelas quais ele se realiza. (GARCIA, 2001, p.29)

O autor considera o monitoramento um requisito imprescindível para o exercício da avaliação como instrumento de gestão governamental, conceituando-o como um processo contínuo que, produzindo informações relevantes, precisas, sintéticas e em tempo eficaz, permite a rápida avaliação situacional e a tomada de decisão e intervenção oportuna que confirma ou corrige as ações monitoradas.

Entretanto, em qualquer situação, nenhum dado ou informação será útil se não estiver apoiado em um contexto que seja conhecido, que faça sentido ou que possa ser monitorado adequadamente. Para tanto, a contextualização dos fatos e a formação de sentido devem ser consideradas uma etapa que, tal como o planejamento, incorpore as seguintes características propostas por Oliveira (2014): preparatória: analisa e considera atos e fatos, situações e ações, soluções reais e possíveis, preparando e municiando o gestor na tomada de decisão futura; condicionadora: direciona o estado atual de coisas em toda a sua complexidade para o futuro, tornando-o dependente e relacionando as decisões presentes à tomada de decisão futura; e prospectiva: impõe ao gestor a ampla consideração de consequências futuras às decisões presentes.

Mintzberg, Ahlstrand e Lampbel (2010), ao tratarem da gestão estratégica, abordam a escola cognitiva como um processo mental que constrói ou interpreta o ambiente no qual a organização está inserida, a partir de informações ricas e ambíguas, complexas e contraditórias que precisam ser interpretadas para que façam sentido. Ao mesmo tempo, a escola do aprendizado, também citada por aqueles autores, afirma que as realidades políticas requerem um processo de aprendizagem coletiva, o que coloca, implicitamente, o monitoramento ambiental nesse contexto posto que, uma vez circunstanciada, a informação, no campo das políticas públicas, adquire valor para tomada de decisão futura e formulação de estratégias no que diz respeito a ações de revisão, melhoria ou aperfeiçoamento de determinada realidade social vigente.

\section{Monitoramento ambiental e Aprendizagem Organizacional}

Um fato isolado, pontual, não tem significado e, portanto, deve ser inserido em um contexto. O monitoramento ambiental possibilita a compreensão do contexto, e a compreensão do contexto permite projetar o desenvolvimento futuro e perceber a teia de relações causais que sustentam um fato. $\mathrm{Na}$ medida em que permite a apreensão do contexto e a produção de conhecimento acerca da ambiência, o monitoramento ambiental possibilita, também, o aprendizado organizacional.

Sob a ótica da informação, Choo (2011) vê o aprendizado organizacional como:

um ciclo contínuo de atividades que envolvem sentir o ambiente, desenvolver percepções e gerar sentido por meio da interpretação, utilizando-se a memória sobre a experiência do passado para auxiliar a percepção e a execução da ação com base nas interpretações desenvolvidas. (CHOO, 2011, p. 43).

De acordo com Choo (2011), sentir é coletar informações sobre os ambientes externo e interno, colher amostras de eventos para a aprendizagem, filtrar mensagens recebidas e selecionar áreas para análise mais apurada. Desenvolver percepções é identificar eventos e entidades externas e descrições sobre eles, utilizando o conhecimento que está disponível na memória, esta derivada das experiências da organização ao interagir com o ambiente. A experiência desenvolve regras e referenciais. As regras são utilizadas para combinar situações com respostas apropriadas, e os referenciais são utilizados para definir problemas e suas dimensões mais 
importantes. A interpretação tenta explicar "o que está acontecendo aqui" em termos significativos e leva à compreensão, ao significado do fato que, por sua vez, conduz à percepção criativa por meio da qual se antecipa e avalia as consequências e oportunidades futuras de acordo com as preferências.

Moresi (2001), apresenta quatro modos de monitoramento ambiental realizados pelas organizações, que podem ser relacionados ao aprendizado organizacional também sob a ótica da informação:

Exposição não condicionada, em que a meta é realizar uma monitoração ampla, para que possam ser detectados sinais de mudança antecipadamente, sendo usadas muitas e variadas fontes de informação; Exposição condicionada, onde o objetivo é avaliar o significado da informação encontrada, para que se possa dimensionar a natureza geral do impacto na organização; Busca informal, em que o objetivo é reunir informação para elaborar um assunto visando determinar a necessidade de atuação no ambiente organizacional; Busca formal, onde o objetivo é sistematicamente recuperar informação relevante sobre um assunto para prover uma base de desenvolvimento de uma decisão ou de uma ação (MORESI, 2001, p.44).

Conclui-se que o aprendizado organizacional, no campo da avaliação das políticas públicas e sob a ótica da Ciência da Informação, é fruto da prospecção, análise e compreensão informacional que devem ocorrer no processo de tomada de decisão quanto à formulação de estratégias de revisão, melhoria ou aperfeiçoamento de políticas e programas sociais em vigor. É fruto, portanto, do monitoramento ambiental.

\section{Ferramentas de monitoramento ambiental e a avaliação de políticas públicas}

A abordagem instrumental da avaliação de políticas púbicas, segundo Faria (2005) é relativa ao apoio às decisões e à busca de resolução de problemas.

Considerando essa instrumentalidade, o monitoramento ambiental, como objeto de prospecção, compreensão informacional, tradução de sinais fracos, contextualização e criação de sentido a respeito de fatos e evidências relacionados a dada política ou programa social, pode apontar para a tomada de decisão proativa no processo de revisão, melhoria ou aperfeiçoamento de estratégias que visam alcançar os objetivos propostos.

Nessa linha de pensamento, e direcionadas ao aprimoramento das políticas públicas e de seus sistemas componentes, algumas ferramentas contemporâneas podem ser utilizadas, pautadas na internet 2.0 (ou Web 2.0), um conceito que se refere à utilização da internet como plataforma de busca, acesso, recuperação, organização, compartilhamento e disseminação da informação pelas pessoas, de forma democrática e colaborativa.

Lopes (2013), ao analisar a utilização das ferramentas da Web 2.0 para o monitoramento do ambiente externo das organizações, denomina de convergência tecnológica a possibilidade de acesso a vários tipos e fontes de informação a partir da mesma plataforma (a internet), a exemplo dos blogs e das wiki. E aborda a cultura da convergência, a ampla utilização da internet como fonte de informação, que permite a todos os membros de uma organização a coleta e o compartilhamento de informação relevante para o desempenho de suas funções e para o sucesso da firma, melhorando a comunicação e promovendo o aprendizado organizacional.

No quesito aprendizagem organizacional, o autor ressalta a construção e manutenção de comunidades de prática, grupo de pessoas que buscam encontrar meios de melhorar o que fazem ou de solucionar um problema, por intermédio da interação e do compartilhamento de informações relevantes que vão recolhendo em várias fontes. Essas informações podem ser complementadas com a inclusão de novos conteúdos, como nas wiki, sendo possível a construção de uma visão mais rica a respeito do que está acontecendo no ambiente externo, a exemplo dos blogs.

Dito isso, no contexto da avaliação de políticas públicas, algumas ferramentas de monitoramento ambiental podem ser utilizadas para a compreensão informacional, a tradução de sinais fracos, a contextualização e a criação de sentido a respeito das políticas e programas sociais destacados em sua agenda, conforme a seguir:

\section{Monitoramento de notícias}

De acordo com Lemos, Barbosa e Borges (2011), como processo informacional, o monitoramento de notícias ou clipping (corte ou recorte, em inglês) é um recorte do que é noticiado pela mídia, de interesse da organização. Utiliza a leitura e o tratamento das notícias como fonte de informação e de compreensão do contexto.

Ainda para aqueles autores, baseado em fontes impessoais externas, tais como jornais, periódicos, rádio, televisão, materiais publicitários, internet, publicações governamentais, o clipping é um sistema contínuo de exame, isto é, um processo sistemático, ininterrupto e contínuo de coleta de informações oriundas do ambiente externo, que possibilita seu acompanhamento e análise constante. E sob a perspectiva mercadológica, 
financeira, jurídica, de empresas e produtos, político-social, cultural, econômica, regulatória, tecnológica, internacional ou de políticas públicas, oferece informações relevantes sobre tendências de mercado e ações de governo, podendo ser usado como suporte ao processo decisório.

Lemos, Barbosa e Borges (2011), relacionam três tipos de monitoramento de notícias: a) clássico: recorte de notícias, reportagens, artigos, editoriais, principais colunas de periódicos impressos ou on line; b) sinopse: resumo das principais notícias de interesse da organização, disponíveis naquelas mesmas interfaces; c) análise: interpretação crítica das informações (análise de conteúdo), descortinando intenções e dados omitidos.

Acrescenta-se aqui um quarto tipo: o clipping eletrônico, pelo qual monitoram-se, com auxílio de tecnologias da Web 2.0, tais como os motores de busca e robôs de notícias e das ferramentas de Tagging, assuntos de interesse da organização em portais, sites, webjornais e blogs.

O monitoramento de notícias, então, em quaisquer de seus modelos, utilizado como ferramenta de monitoramento ambiental, auxilia no processo de avaliação de políticas públicas, posto que a leitura e o tratamento sistemático de notícias (boas ou más) relacionadas a uma determinada política ou programa social definidos permitem a compreensão do contexto, a interpretação da situação e a tomada de decisão quanto a possíveis ações de se avaliar a eficácia, a eficiência, a economicidade de projetos e programas de governo e seus resultados sociais, bem como aferir indicadores para o fortalecimento da gestão pública.

\section{Redes sociais}

De acordo com Reiter e Battisti (2012) uma rede social é uma estrutura social composta por pessoas ou organizações, conectadas por um ou vários tipos de relações, que partilham valores e objetivos comuns. Uma das características fundamentais na definição das redes é a sua abertura e porosidade, possibilitando relacionamentos horizontais e não hierárquicos entre os participantes. As Redes Sociais podem operar em diferentes níveis, por exemplo, redes de relacionamentos (Facebook, MySpace, Twitter), redes profissionais (Linkedin), redes comunitárias (redes sociais em bairros ou cidades), redes políticas, entre outras.

Um ponto em comum dentre os usuários dos diversos tipos de rede social é o compartilhamento de informações, conhecimentos, interesses e esforços em busca de objetivos comuns. A intensificação da formação das redes sociais, nesse sentido, reflete um processo de fortalecimento da sociedade civil, em um contexto de maior participação democrática e mobilização social.

Rezende e Lopes (2011), realizaram estudo sobre o uso das redes sociais no processo de monitoramento ambiental, tomando-as como fontes de informação para a tomada de decisão. Concluíram que as redes sociais não podem ser ignoradas, pois têm as relações interpessoais como premissa básica, direcionadas geralmente por comportamentos de grupos que possuem valores ou opiniões em comum, proporcionando àqueles que praticam o monitoramento ambiental, possibilidades de questionar suposições e criar novas interpretações. Ademais, compuseram um quadro no qual associaram os modos de monitoramento ambiental apresentado por Moresi (2001), ao uso das redes sociais para obtenção de informação relevante e criação de contexto a respeito da ambiência externa.

Seguindo então nessa mesma trilha, e considerando a definição de Valla (1998) de que participação popular compreende as múltiplas ações que diferentes forças sociais desenvolvem para influenciar a formulação, execução, fiscalização e avaliação das políticas públicas e/ou serviços básicos na área social, e de que é necessário levar em conta a visão das pessoas e coletividades sobre os seus problemas e sobre as soluções que constroem, caracteriza-se aqui também, a importância das redes sociais no contexto da avaliação de políticas públicas, conforme aponta o quadro a seguir:

Quadro 1 - Modos de monitoramento ambiental com utilização de redes sociais para avaliação de políticas públicas

\begin{tabular}{|c|l|l|}
\hline Modos de monitoramento & \multicolumn{1}{|c|}{ Definição e objetivos } & \multicolumn{1}{|c|}{$\begin{array}{c}\text { Uso das redes sociais para } \\
\text { avaliação de políticas públicas }\end{array}$} \\
\hline Visualização indireta & $\begin{array}{l}\text { Monitoração ampla } \\
\text { Objetivo: detectar mudanças } \\
\text { antecipadamente } \\
\text { Utiliza várias fontes de informação. }\end{array}$ & $\begin{array}{l}\text { Podem ser amplamente utilizadas } \\
\text { para identificar mudanças de } \\
\text { comportamento dos usuários e } \\
\text { membros, de forma antecipada. }\end{array}$ \\
\hline
\end{tabular}

Fonte: adaptado de Rezende e Lopes (2011) 
Quadro 1 - Modos de monitoramento ambiental com utilização de redes sociais para avaliação de políticas públicas (Continuação)

\begin{tabular}{|c|c|c|}
\hline Modos de monitoramento & Definição e objetivos & $\begin{array}{c}\text { Uso das redes sociais para } \\
\text { avaliação de políticas públicas }\end{array}$ \\
\hline Visualização condicionada & $\begin{array}{l}\text { Interesse em tópicos específicos } \\
\text { Objetivo: avaliar o significado da } \\
\text { informação encontrada } \\
\text { Geralmente não dedica esforço e } \\
\text { tempo substanciais }\end{array}$ & $\begin{array}{l}\text { Podem ser utilizadas para } \\
\text { acompanhar comunidades que } \\
\text { compartilham opiniões sobre } \\
\text { determinadas políticas públicas ou } \\
\text { programas sociais. }\end{array}$ \\
\hline Procura informal & $\begin{array}{l}\text { Busca-se informação para aprofundar } \\
\text { o conhecimento sobre um assunto } \\
\text { específico. } \\
\text { Objetivo: reunir informações sobre um } \\
\text { assunto, para determinar a } \\
\text { necessidade de atuação no ambiente } \\
\text { organizacional. }\end{array}$ & $\begin{array}{l}\text { Podem ser utilizadas para identificar } \\
\text { preferências e tendências de grupos } \\
\text { de usuários ou participantes a } \\
\text { respeito de determinado aspecto de } \\
\text { uma política ou programa de } \\
\text { governo. } \\
\text { Podem apontar para a necessidade } \\
\text { de avalição da efetividade de } \\
\text { determinada política ou programa. }\end{array}$ \\
\hline Procura formal & $\begin{array}{l}\text { Realiza-se esforço deliberado ou } \\
\text { planejado para obter informação } \\
\text { específica ou sobre um determinado } \\
\text { assunto ou necessidade. } \\
\text { Objetivo: recuperar informação } \\
\text { relevante sobre um assunto, para } \\
\text { prover uma base de desenvolvimento } \\
\text { de uma decisão ou linha de ação } \\
\text { Utiliza metodologias específicas e } \\
\text { fontes fidedignas. }\end{array}$ & $\begin{array}{l}\text { Podem ser utilizadas para sinalizar } \\
\text { tendências e comportamentos que } \\
\text { complementarão a busca da } \\
\text { informação específica. } \\
\text { Podem apontar para a necessidade } \\
\text { de revisão de determinada política } \\
\text { ou programa. }\end{array}$ \\
\hline
\end{tabular}

O monitoramento ambiental por intermédio de redes sociais, nesse sentido, reflete um processo de fortalecimento do controle social sobre o Estado e um contexto de participação democrática posto que, nesse caso, a obtenção de informação relevante e a criação de contexto a respeito da ambiência externa relacionada a políticas e programas de governo têm origem nas manifestações e opiniões da sociedade civil sobre o tema. Isso permite a interpretação da situação e a tomada de decisão quanto a possíveis ações avaliativas ou de estratégias de revisão ou aperfeiçoamento de ação governamental.

\section{Metadados}

Moresi, Prado e Alcântara (2010), apresentam o uso de metadados na qualificação, classificação e mapeamento das fontes de informação e da própria informação para adicionar qualidade aos resultados que podem ser obtidos com o Monitoramento Ambiental, e apresentam a seguinte definição para o termo:

metadado é todo dado utilizado para descrever, indexar, recuperar ou qualificar dados ou fontes de dados, sejam estes (dados ou fontes) estruturados em bases de dados ou não, obtidos por meio de tecnologia ou não, para utilização em quaisquer sistemas de informação com propósitos de atender a necessidades de negócios, tecnologia e usuários, devendo fornecer contexto e podendo indicar o grau de qualidade relativo aos mesmos. (ALCANTARA, MORESI e PRADO, 2004).

Para eles, o uso de metadados durante o processo de monitoração ambiental:

pode identificar vários fatores de qualificação, tipificação e indexação dos elementos da Monitoração Ambiental: onde reside a informação, qual o setor da sociedade onde a informação foi produzida, quando a informação foi produzida, quem a avaliou, se a fonte é confiável, se a informação é confiável, 
se é acessível por algum sistema de informação interno à organização, se é informação do tipo pública ou restrita, se é do tipo estratégica, tática ou operacional, se é relativa a conhecimentos estáveis, dinâmicos ou de estimativas futuras, se é formal ou informal, se é global, regional, ou local, se a Monitoração Ambiental realizada para obtenção dos resultados ocorreu de forma intrusiva ou de acesso público, enfim, inúmeros atributos que produzem contexto à informação que foi obtida durante a Monitoração Ambiental. (MORESI, PRADO e ALCÂNTARA, 2010).

No âmbito das redes sociais, baseadas na Web 2.0, os metadados podem ser gerados a partir da folksonomia, termo empregado para designar a etiquetagem realizada pelo próprio usuário da informação. Segundo Catarino e Baptista (2007):

trata-se de uma indexação livre em linguagem natural, não são adotadas regras e/ou políticas de indexação e nem o controle de vocabulários, ou seja, não há efetivamente a tradução dos termos para uma linguagem artificial. Os conteúdos são indexados livremente pelos usuários do recurso, podendo representar assuntos ou quaisquer outros elementos de metadados tais como tipo ou formato. (CATARINO e BAPTISTA, 2007).

E quanto à utilização de metadados, independentemente se originados na folksonomia ou no padrão Dublin Core para busca, recuperação, organização e disseminação de informações, o que importa, no contexto da avaliação de políticas públicas e programas sociais, é que o participante do ambiente digital tem acesso aos outros participantes que possuem os mesmos interesses identificados através das tags, ou palavras-chave. Isso possibilita, conforme Moresi, Prado e Alcântara (2010) a obtenção "de várias análises de fontes de dados de diversos avaliadores, comparar avaliações de informações de diversos avaliadores e também comparar uma informação de um determinado assunto através de várias fontes distintas".

\section{Considerações sobe o uso da IC no contexto do legislativo}

O Poder Legislativo é o meio de representação da sociedade para que suas necessidades e conflitos sejam convertidos em políticas públicas. Conforme Cardoso Filho (2012), essas políticas são originárias de temas e problemas que, apontados pela sociedade, constituem uma agenda repleta de questões, tais como a questão fundiária, emprego e renda, saúde, educação, transportes, segurança, saneamento, cidadania, entre outros temas não menos importantes.

Ao abordarem o tema avaliação de políticas públicas no Senado Federal, Freitas et al. (2013), afirmam que:

de acordo com a doutrina e a jurisprudência, a tarefa de formular e executar políticas públicas reside prioritariamente nos poderes Legislativo e Executivo. Afinal, esses são os órgãos que possuem legitimidade democrática direta para a definição dos rumos políticos do governo, uma vez que são eleitos pelo voto direto da população. (FREITAS et al., 2013, p.11).

Partindo dessa premissa, compreende-se que o Legislativo contribui fortemente no ciclo das políticas públicas. Considerando, então, esse ciclo e a legitimidade que o poder Legislativo possui, tanto no que preza a Constituição Federal quanto as Constituições Estaduais, assim como a Lei Orgânica do Distrito Federal e as Leis Orgânicas dos Municípios, as ferramentas da $\mathrm{Cl}$ apresentadas neste texto podem ser assim utilizadas em cada fase, conforme Cardoso Filho (2012):

a. na formação da agenda, a inteligência competitiva e a inteligência estratégica antecipativa são adequadas para serem utilizadas, pois o monitoramento ambiental e a percepção de sinais fracos advindos dos cenários socioeconômicos e políticosociais permitem perceber tensões e inferir exigências de mudanças nesse ambiente;

b. na formulação, implementação, análise, avaliação e fiscalização, a gestão da informação e do conhecimento se faz forte, considerando-se, nessas etapas, a necessidade de aquisição, organização e armazenagem da informação, o desenvolvimento de produtos informacionais e de serviços de distribuição e o uso da informação como recurso econômico e estratégico para acompanhamento e melhor atuação político-decisória. (CARDOSO FILHO, 2012, p.126). 
sentido para tomada de decisão a respeito de políticas públicas e programas sociais destacados em uma agenda.

Quadro 2. Proposta metodológica de utilização instrumental das ferramentas de monitoramento ambiental para tomada de decisão em Políticas Públicas

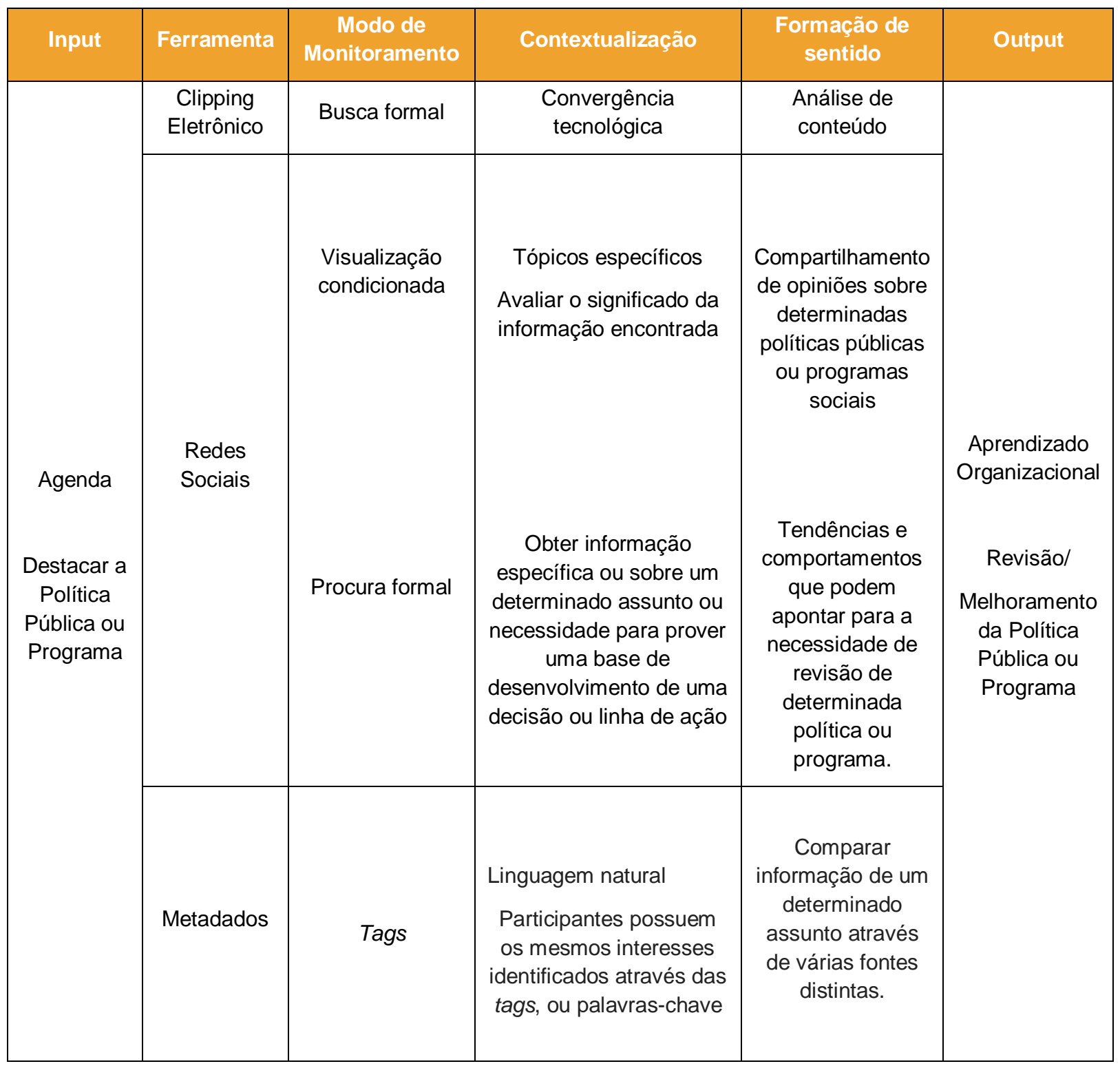

Fonte: dos autores

Entendido como um sistema de informações, o quadro acima aponta como entrada a agenda definida, ou seja, a política pública ou programa a ser monitorado para análise e avaliação. Após, na fase de processamento, utilizam-se as ferramentas disponíveis, tal como apresentado anteriormente, com busca e recuperação formal da informação, contextualização, organização, análise, compreensão informacional e formação de sentido; e produção de conhecimento e inteligência para decisão estratégica de revisão, melhoria ou aperfeiçoamento das políticas ou programas considerados. O exercício sistemático desse monitoramento permitirá a percepção de tensões e inferir exigências de maior acompanhamento, análise e revisão das políticas públicas em observação.

\section{Conclusão}

Claro está que a interdisciplinaridade entre a Ciência da Informação e as Políticas Públicas é um campo de estudos vasto e estimulante. Nessa direção, a contribuição da Ciência da Informação para tais estudos pode concentrar-se na visão da $\mathrm{Cl}$ orientada para os meios que devem ser usados na prática da atividade de informação em Políticas Públicas, tais como o monitoramento ambiental, que permite a percepção de sinais fracos advindos dos cenários socioeconômicos e político-sociais e a percepção de tensões e exigências de 
mudanças nesse ambiente. Ou na visão orientada para a tecnologia, interessada em metodologias de armazenagem e recuperação de dados. Ou, ainda, na visão orientada para os fins, definida a partir do ponto de vista de que existem determinadas necessidades sociais a serem preenchidas, e que a $\mathrm{Cl}$ deve servir a essas necessidades e oferecer ao campo das Políticas Públicas o uso da informação como recurso econômico e estratégico para acompanhamento e melhor atuação político-decisória.

Por fim, independentemente da abordagem utilizada, no que diz respeito à atuação do Poder Legislativo no campo da Políticas Públicas, as Casas Legislativas, ao adotarem, desde a Ciência da Informação, o Monitoramento Ambiental e suas ferramentas acessórias, estarão aptas a monitorar o ambiente econômico e social e a visão das pessoas e coletividades sobre os seus problemas e as ações que adotam para solucionálos, a identificar de forma consistente as mudanças ambientais que impactam na formação da agenda, formulação, análise e avaliação de políticas públicas, e fortalecer o controle social, cada vez mais exigido na sociedade da informação.

\section{Referências}

AGUILAR, M. J.; ANDER-EGG, E. Avaliação de serviços e programas sociais. Petrópolis: Vozes, 1994.

ALBUQUERQUE, S. F. de; ARAÚJO JÚNIOR, R. H. de. Representação e organização da informação em núcleos de inteligência competitiva. In: BAPTISTA, D. M.; ARAÚJO JÚNIOR, R. H. de. (Orgs) Organização da informação: abordagens e práticas. Brasília: Thesaurus, 2015.

ARAÚJO JÚNIOR, R. H. de; PERUCCHI, V.; LOPES, P. R. D. Analise bibliométrica dos temas inteligência competitiva, gestão do conhecimento e conhecimento organizacional no repositório institucional da Universidade de Brasília. Perspectivas em Ciência da Informação, v.18, n.4, p.54-69, out. /dez. 2013.

BARRETO, A. de A. As tecnologias intensivas de informação e comunicação e o reposicionamento dos atores do setor. INFO 97, Cuba, outubro de 1997.

BELLONI, I.; MAGALHES, H. de; SOUSA, L. C. de. Metodologia de avaliação em políticas públicas: uma experiência em educação profissional. 4. ed. São Paulo: Cortez, 2007.

BORKO, H. Information science: what is it? American Documentation, v. 19, n. 1, p. 3-5, 1968.

BROOKES, B. C. The foundations of information science. Part I. Philosophical aspects. Journal of Infomation Science, n.2, p.125-133, 1980. Disponível em: <http://www.uff.br/cienciainformacao/Disciplinas/Brooks-Foudations\%20of\%20IS-P-I.pdf> Acesso em: 11 jun. 2015.

CARDOSO FILHO, J. C. Identificação de competências individuais em atividade de fiscalização e controle externo na Câmara Legislativa do Distrito Federal. Dissertação (Mestrado em Ciência da Informação) - Universidade de Brasília, Brasília, 2003.

CARDOSO FILHO, J. C. Competências emergentes do Legislativo para políticas públicas: estudo de caso da CLDF. In: MIRANDA, R. C. da R. (org.). Informação e conhecimento no Legislativo. Brasília: Câmara dos Deputados, 2012.

CARVALHO, V. A. de; SILVA, M. do R. de F. E. Política de segurança pública no Brasil: avanços, limites e desafios. R. Katál. v. 14, n. 1, p. 59-67, jan. /jun. 2011. Disponível em: <http://www.scielo.br/pdf/rk/v14n1/v14n1a07.pdf>. Acesso em 09 jun. 2015.

CATARINO, M. E.; BAPTISTA, A. A. Folksonomia: um novo conceito para a organização dos recursos digitais na Web. Data Grama Zero, v. 8, n. 3. jun., 2007. Disponível em: <http://www.dgz.org.br/jun07/Art_04.htm>. Acesso em: 09 jun. 2015.

CHOO, C. W. Aprendizado como inteligência organizacional. In: TARAPANOFF, K. (Org) Aprendizado organizacional e abordagens multidisciplinares. v.1. Curitiba: Ibpex, 2011.

CUNHA, C. D. da. A construção de um novo paradigma de segurança pública como política social: a experiência da política de prevenção à criminalidade no Estado de Minas Gerais. In: II Simpósio mineiro de Assistentes Sociais: Expressões socioculturais da crise do capital e as implicações para a garantia dos direitos sociais e para o serviço social. Belo Horizonte, 2013. Disponível em: <http://www.cress-mg.org.br/hotsite/1/paginas/home.php?pg=5>. Acesso em 11 jun. 2015.

DISTRITO FEDERAL (Brasil). Câmara Legislativa. Resolução no 261, de 2013. Insere dispositivos no Regimento Interno da Câmara Legislativa do Distrito Federal para criar a Comissão de Fiscalização, Governança, Transparência e Controle e dá outras providências. Diário da Câmara Legislativa do Distrito Federal, Brasília, DF, 15 jan. 2013, n. 10, p. 1. Disponível em: <http://www.cl.df.gov.br/documents/5744638/5069193/DCL+n\%C2\%BA\%20010\%2C\%20de+15+de+janeiro+de+2013>. Acesso em: 09 jun. 2015.

FARIA, C. A. P. de. A política da avaliação de políticas públicas. Revista Brasileira de Ciências Sociais, v. 20, n. 59, out. 2005. Disponível em: <http://www.scielo.br/scielo.php?script=sci_arttext\&pid=S0102-69092005000300007\&lng=pt\&nrm=iso>. Acesso em 09 jun. 2015. 
FLEURY, S.; OUVERNEY, A. L. M. Política de Saúde: uma Política Social. In: GIOVANELLA, L.; ESCOREL, S.; LOBATO, L. de V. C.; NORONHA, J. C. de; CARVALHO, A. I. de. (Orgs.). Políticas e Sistemas de Saúde no Brasil. Rio de Janeiro: FIOCRUZ, 2008, p. 23-64.

FREITAS, I. V. B. de; TANCREDI, M.; CAVALCANTE FILHO, J. T.; MENEGUIN, F. B. Avaliação de políticas públicas no Senado Federal: proposta de abordagem. Brasília: Senado Federal, 2013. Disponível em: <http://www12.senado.gov.br/publicacoes/estudos-legislativos/tipos-de-estudos/outras-publicacoes/avppsf/avaliacao-depoliticas-publicas-no-senado-federal-1>. Acesso em: 17 nov. 2014.

GARCIA, R. C. Subsídios para organizar avaliações da ação governamental. Planejamento e Políticas Públicas, n. 23, 2001. Disponível em: <http://www.ipea.gov.br/ppp/index.php/PPP/article/view/72>. Acesso em: 19 nov.2014.

LEMOS, A. B.; BARBOSA, R. R.; BORGES, M. E. N. O monitoramento de notícias como ferramenta para a inteligência competitiva. Pesquisa Brasileira em Ciência da Informação e Biblioteconomia, vol. 6, n 2, 2011. Disponível em: <http://periodicos.ufpb.br/ojs/index.php/pbcib/article/view/13334>. Acesso em: 11 jun. 2015.

LESCA, H.; FREITAS, H.; MUNIZ, R. J. Inteligência antecipativa para decisão estratégica. Organizações em Contexto, v. 2, n. 4, p. 92-118, dez. 2006.

LOPES, S. P. M. A Web 2.0 como ferramenta de análise de tendências e monitorização do ambiente externo e sua relação com a cultura de convergência dos media. Perspectivas em Ciência da Informação, v.18, n.1, p.126-137, jan. /mar. 2013.

MINTZBERG, H.; AHLSTARAND, B.; LAMPEL, J. Safári de estratégia: um roteiro pela selva do planejamento estratégico. 2.ed. Porto Alegre: Bookman, 2010.

MORESI, E. A. D. Monitoração ambiental e complexidade. 2001. Tese (Doutorado em Ciência da Informação) - Universidade de Brasília.

MORESI, E. A. D.; PRADO, H. A. do; ALCÂNTARA, A. de. Cenários prospectivos, monitoração ambiental e metadados. Data Grama Zero, v. 11, n. 1. fev. 2010. Disponível em: <http://www.dgz.org.br/fev10/Art_04.htm> Acesso em: 09 jun. 2015.

OLIVEIRA, D. A. A educação no contexto das políticas sociais atuais. Linhas Críticas, Brasília, v. 11, n. 20, p. 27-40, jan. /jun. 2005.

OLIVEIRA, D. de P. R. de. Planejamento estratégico: conceitos, metodologia e práticas. 32 ed. São Paulo: Atlas, 2014

PEREIRA, P. A. P. As interfaces da assistência social: destaque à relação com a política de transportes. Revista SER Social, n.12, p. 245-258, 2003. Disponível em: <http://seer.bce.unb.br/index.php/SER Social/article/view/284>. Acesso em: 13 nov. 2014.

REITER, M. E. F.; BATTISTI, G. OpenSocial: Uma Nova Forma de Interação. Data Grama Zero, v.13, n.2, abr., 2012. Disponível em: <http://www.dgz.org.br/abr12/Art_03.htm>. Acesso em 11 jun. 2015.

REZENDE, L. V. R.; LOPES, A. P. O Uso das Redes Sociais do Ciberespaço como Estratégia de Monitoramento Ambiental. XXIV Congresso Brasileiro de Biblioteconomia, Documentação e Ciência da Informação. Maceió, 2011. Disponível em: <http://febab.org.br/congressos/index.php/cbbd/xxiv/paper/view/539>. Acesso em: 11 jun. 2015.

SANO, H.; MONTENEGRO FILHO, M. J. F. As Técnicas de Avaliação da Eficiência, Eficácia e Efetividade na Gestão Pública e sua Relevância para o Desenvolvimento Social e das Ações Públicas. Desenvolvimento em Questão, v. 11, n. 22, p. 35-61, jan. /abr. 2013. Disponível em: <https://www.revistas.unijui.edu.br/index.php/desenvolvimentoemquestao/article/view/186> Acesso em: 15 nov. 2014

SANTOS, M. M.; CARDOSO FILHO, J. C. Informação e políticas públicas: responsabilidade social da Ciência da Informação. Biblios, n. 45, 2011. Disponível em: < http://biblios.pitt.edu/ojs/index.php/biblios/article/view/26/75>. Acesso em: 11 jun. 2015.

SARACEVIC, T. Interdisciplinary nature of Information Science. Ciência da Informação, Brasília, v.24, n.1, p.36-41, 1995.

SOUZA, C. Políticas públicas: uma revisão da literatura. Sociologias, v.8, n.16, p. 20-45, jul. /dez., 2006.

VALLA, Victor Vincent. Sobre participação popular: uma questão de perspectiva. Cadernos de Saúde Pública, Rio de Janeiro, v.14 (Sup.2), p.7-18, 1998.

WERSIG, G.; NEVELING, U. The phenomena of interest to Information Science. Information Scientist, v. 9, n.4, p. 127-140, Dec., 1975. Disponível em: <http://sigir.org/files/museum/pub-13/18.pdf>. Acesso em: 11 jun. 2015 


\title{
Dados dos autores
}

\author{
Jair Cunha Cardoso Fillho
}

Consultor Técnico-Legislativo na Câmara Legislativa do Distrito Federal. Graduado em Administração. Mestre e Doutorando em Ciência da Informação na Universidade de Brasília - UnB.

jaircardosofilho@uol.com.br

Rogério Henrique de Araújo Júnior

Professor Doutor, da Faculdade de Ciência da Informação da Universidade de Brasília - UnB.

rogerio.araujo.jr@gmail.com

Recebido - Received: 2015-06-16

Aceitado - Accepted: 2015-10-08

\section{(c) EY}

This work is licensed under a Creative Commons Attribution 4.0

United States License.

\section{ULLS D-Sorte}

This journal is published by the University Library System of the University of Pittsburgh as part of its D-Scribe Digital Publishing Program and is cosponsored by the University of Pittsburgh Press. 